This item was submitted to Loughborough's Research Repository by the author.

Items in Figshare are protected by copyright, with all rights reserved, unless otherwise indicated.

\title{
Effect of a dual-mass flywheel on the impact-induced noise in vehicular powertrain systems
}

PLEASE CITE THE PUBLISHED VERSION

PUBLISHER

Professional Engineering Publishing / @ IMECHE

VERSION

VoR (Version of Record)

LICENCE

CC BY-NC-ND 4.0

\section{REPOSITORY RECORD}

Theodossiades, Stephanos, M. Gnanakumarr, Homer Rahnejat, and P. Kelly. 2019. "Effect of a Dual-mass Flywheel on the Impact-induced Noise in Vehicular Powertrain Systems". figshare. https://hdl.handle.net/2134/4745. 
This item was submitted to Loughborough's Institutional Repository (https://dspace.lboro.ac.uk/) by the author and is made available under the following Creative Commons Licence conditions.

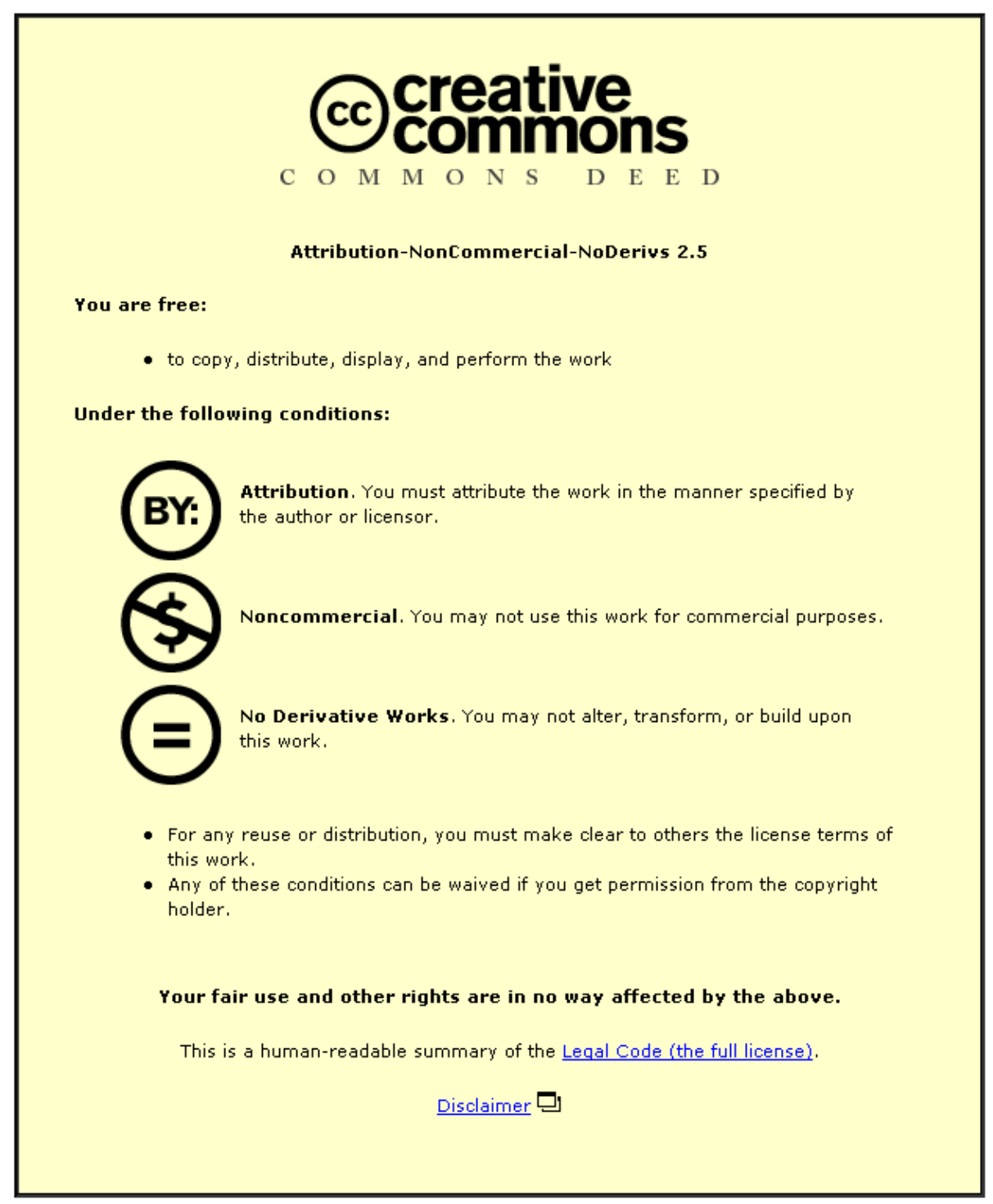

For the full text of this licence, please go to: http://creativecommons.org/licenses/by-nc-nd/2.5/ 


\title{
Effect of a dual-mass flywheel on the impact-induced noise in vehicular powertrain systems
}

\author{
S Theodossiades $^{1 *}$, M Gnanakumarr ${ }^{1}$, H Rahnejat $^{1}$, and P Kelly ${ }^{2}$ \\ ${ }^{1}$ Wolfson School of Mechanical and Manufacturing Engineering, Loughborough University, Loughborough, \\ Leicestershire, UK \\ ${ }^{2}$ Powertrain Engineering, Ford Werke GmbH, Cologne, Germany
}

The manuscript was received on 15 March 2005 and was accepted after revision for publication on 10 March 2006.

DOI: 10.1243/09544070JAUTO55

\begin{abstract}
The appearance and persistence of impact-induced clonk noise in rear wheel drive light truck drivelines has led to an urgent need for remedial action. The pressure for delivering results within tight schedules and financial constraints has resulted in palliative actions rather than fundamental investigations. It has been speculated that the use of a dual-mass flywheel (DMF) can lead to attenuation of clonk metallic noise, even though its main purpose has been to counter transmission rattle by reducing the input torsional impulse. The present work investigates the effect of DMF on impact-induced clonk noise and its severity through experimentation. Sound measurements in the driveline only reveal a slight reduction in the overall levels of impact-induced noise, but a significant change in its quality - the sharpness associated with the typical metallic content of clonk is absent. The effect is also highlighted by the main frequency content of the response when DMF is employed. The duration of the clonk phenomenon is altered from the case where a traditional single solid-mass flywheel is employed.
\end{abstract}

Keywords: powertrains, driveline clonk, transmission rattle, dual-mass flywheel, solid-mass flywheel

\section{INTRODUCTION}

The trend for reduction in fuel consumption is mainly realized through improved combustion strategies, increased output power, and reduced inertial content. The combination of these, however, has brought about the undesired effect of increased torsional vibration and noise in the drivetrain, which is then transferred into the cabin interior [1]. The above factors are of course among many other parameters that can affect fuel efficiency, such as aerodynamics and tyre-road interactions.

The first dual-mass flywheel (DMF) configurations in vehicular powertrain systems appeared more than 25 years ago. They were principally designed as a means to reduce significantly the torsional impulses

* Corresponding author: Wolfson School of Mechanical and Manufacturing Engineering, Loughborough University, Loughborough, Leicestershire,LE11 3TU,UK.email: s.theodossiades@ lboro.ac.uk in the gearbox, which are caused by fluctuations of the engine power output. In conventional designs, the torsional resonance lies between 700 and $2000 \mathrm{r} / \mathrm{min}$. DMF introduces a secondary inertia near the transmission input shaft [Figs 1(a) and (b) ] [2], which shifts the resonance below the engine idle speed. In essence, DMF has introduced two major benefits: lower hysteresis rates than conventional clutches and significant attenuation of engine torsional fluctuations to the transmission, as indicated analytically below in the literature provided.

Use of a twin-mass flywheel for tuning passenger car drivelines was originally suggested by Drexl [3]. It was conceived as a measure to eliminate idle rattle condition and load reversal oscillations. Additionally, it was seen as cost effective compared with more sophisticated systems with controlled slip action and hydrodynamic coupling between the flywheel and the clutch. In another experimental investigation the same author [4] demonstrated the effect of a twinmass flywheel in shifting the natural frequency, which contributes to gear rattle and body panel 


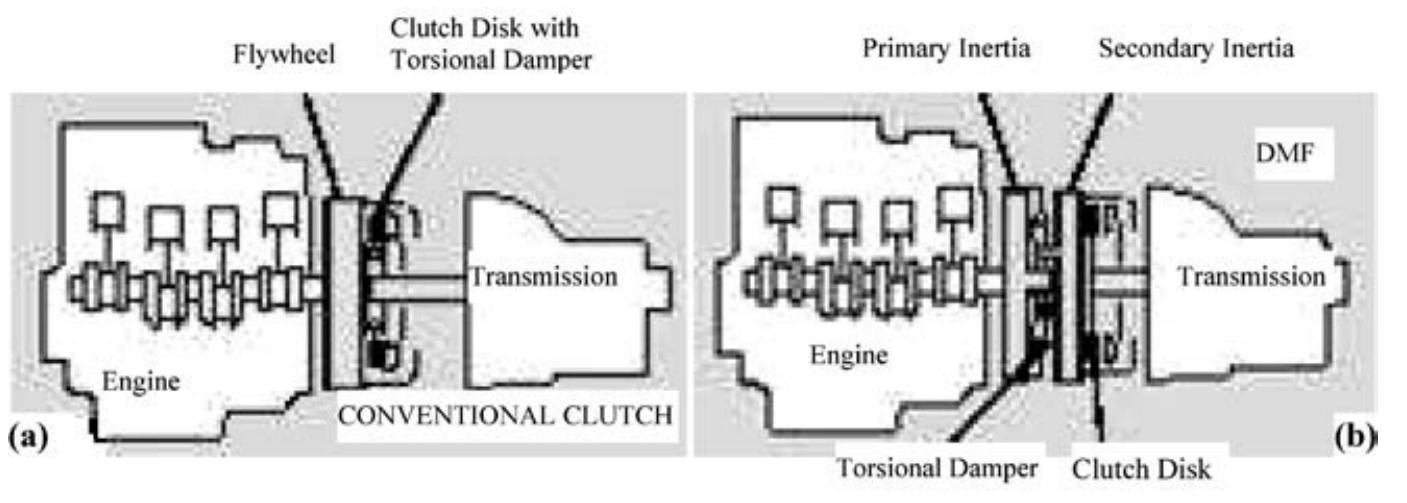

(c)

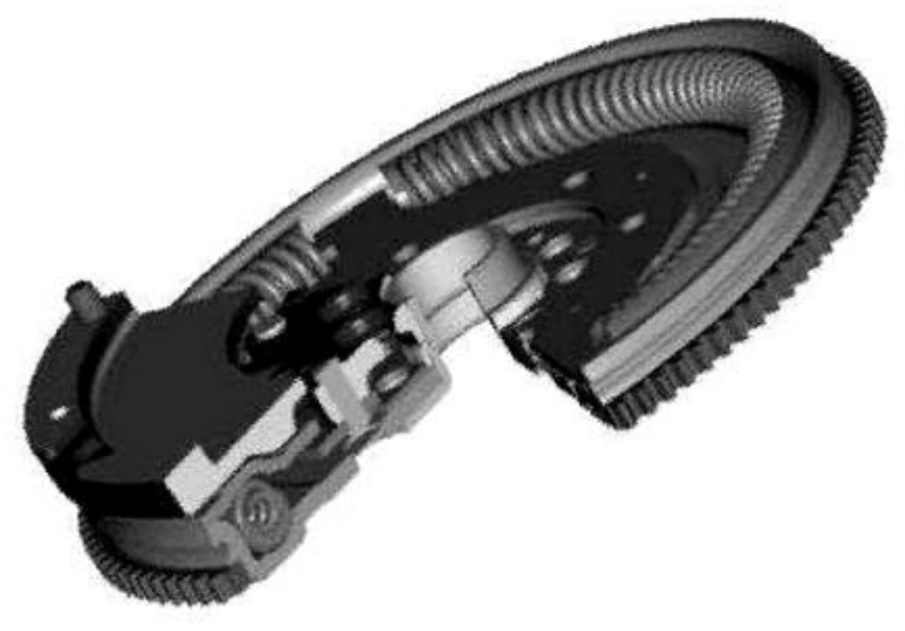

Fig. 1 (a) DMF configuration, (b) conventional clutch configuration, and (c) DMF system for light trucks

vibration noise, onomatopoeically referred to as 'boom'. This was recommended as the only measure that transfers this critical frequency below the driving speed range. Additionally, the twin-mass flywheel was found to attenuate significantly the structure-borne noise of the gearbox housing for engine operations over $1000 \mathrm{r} / \mathrm{min}$.

The effectiveness of DMF designs and hydraulic torsional dampers (HTDs) under investigated rattle and clonk conditions was compared with that of conventional clutches in a numerical investigation [5]. It was concluded that DMF and HTD configurations could offer substantial improvements in both these noise, vibration, and harshness (NVH) concerns. In a later investigation, a new type of DMF design was presented [6] to improve the tip-in/back-out performance (rapid application of throttle from coast to drive condition or rapid release of throttle from drive to coast). It was shown that surging vibration amplitudes decay rapidly. Furthermore, there were no subsequent fluctuations observed in the torsional response of the engine and transmission. However, no data were provided for the quantification of the resulting improvements in the examined $\mathrm{NVH}$ concerns.

The effectiveness of various options for effecting vibration isolation between the engine and the transmission was compared [7] and the DMF was rated as one of the most effective in achieving a smoother response in the transmission during rattle and surging conditions. The aforementioned results were also underpinned by the low cost of this solution compared with other designs with similar performance (active isolation systems, slip coupled hydrodynamic and torque control isolation systems), but with a higher implementation outlay. By developing a powertrain numerical model, where critical non-linear effects (such as gear backlash and friction clutch characteristics) were included [8], Laschet demonstrated the effectiveness of the two-mass flywheel system on isolating the drivetrain from engine excitation. The response was found to have lower amplitude and a smaller number of impacts in the frequency range of interest $(1000-2000 \mathrm{~Hz})$. 
The placement of effective torsional damping within a twin-mass flywheel system, instead of incorporating the same into the clutch system, has resulted in the most effective form of torsional vibration damping, especially in cases of gearbox rattle and axle booming noise as shown in reference [9]. The use of a secondary mass ensures that the natural rattling frequency of the driveline is set below the idle speed. This means that the driveline rattle frequency is outside the normal driving range for all the lower gears.

The above investigations have revealed the beneficial effects of DMF systems on drivetrain torsional vibration during steady state conditions of rattle and boom NVH phenomena. Additionally, some insight was provided into its effect during tip-in and back-out conditions (referred to as shunt), promoting drivetrain clonk noise. However, the main question remaining is the quantification of DMF effectiveness under high-torque transient impulsive action, referred to as driveline clonk, particularly the extent of palliation with regard to radiated noise and its frequency characteristics. The presence of lash zones in the drivetrain (clutch, transmission and differential gears, spline joints, etc.) determines the passage of the transient impulse through the system, interacting with the modal density of elastic components. Clonk is a shortduration (a few milliseconds), audible, high-frequency, elastoacoustic phenomenon that occurs as a result of load reversal in the presence of lashes in the driveline (1500-5000 Hz) [10-12]. It is an onomatopoeic term, given the metallic nature of the radiated noise. The short duration of the torque impulse excites a large number of structural modes of the lightly damped drivetrain system. In particular, components such as the propshafts are effective noise radiators, since they have a very low ratio of wall thickness to diameter. The mode shapes participating in the clonk signal are mainly breathing modes, as has been shown both numerically and experimentally [10-12].

The contribution of the present paper is mainly the examination of vibration and noise effects from the drivetrain propshafts under clonk conditions in a drivetrain including a DMF. Comprehensive measurements of the driveline vibration response and noise radiation were undertaken with a DMF and with a conventional clutch. The results have revealed a substantial difference in the number of modes observed in both the vibration and noise spectra of the aforementioned cases. The effect on the radiated metallic clonk noise is noteworthy, since the impulsive action upon the drivetrain is only capable of exciting a small number of structural modes of the lightly damped driveline system when a DMF is used, as opposed to when a conventional clutch is present.

\section{EXPERIMENTAL CONFIGURATION}

An experimental rig is set up using a three-piece drivetrain system of a light rear wheel drive truck, comprising all components from flywheel to rear axle, including rear wheel assemblies [see Fig. 2(a)]. The basic configuration of the rig remains the same as that in reference [11], except for the inclusion of a DMF and an SGF coupling between the transmission flange and the front driveshaft tube.

An a.c. electric motor drives the drivetrain system through a flexibly coupled propeller shaft mounted on a pair of deep-groove ball bearings. A handbrake system used in a commercial vehicle was modified using an electronic control unit and calibrated in order to operate in a repeatable manner and introduce various laden states of the vehicle by applying resistance via the rear axle. Analytic description of how these loads have been calculated is presented in reference [10]. The rig is designed in a modular construction and assembled in a manner that can accommodate two alternative flywheels; one of single solid-mass construction and another of dual-mass form. Full description of the basic rig configuration is provided elsewhere $[\mathbf{1 0}, \mathbf{1 1}]$. The essential modification to the clutch-transmission assembly (as described in references [10] and [11]) is the replacement of the conventional solid-mass flywheel with the DMF system [Fig. 1(c) [2]). This separates the clutch disk from the torsional predamper [Figs 1(a) and (b)] while bringing an additional inertial element into play. The main effect of the above design is the attenuation of vibrations in the transmission shafts and a smoother passage of engine torque into the drivetrain system.

Clonk, as a sudden high rise rate torsional acceleration impulse (jerk), can be induced in the drivetrain system in a number of ways, including rapid load change due to abrupt clutch actuation. Therefore, the conducted experiments constitute clutch actuation by a driver as the source of excitation. As in reference [11], tests were carried out with the second gear selected, at a motor speed of $1500 \mathrm{r} / \mathrm{min}$, and abrupt clutch disengagement in time intervals of $100-300 \mathrm{~ms}$, based on the data gathered from field trials with actual vehicles under clonk conditions. Thus, clutch-induced clonk was generated in the driveline. As already described, the investigation was concerned with the manifestation of 
(a)

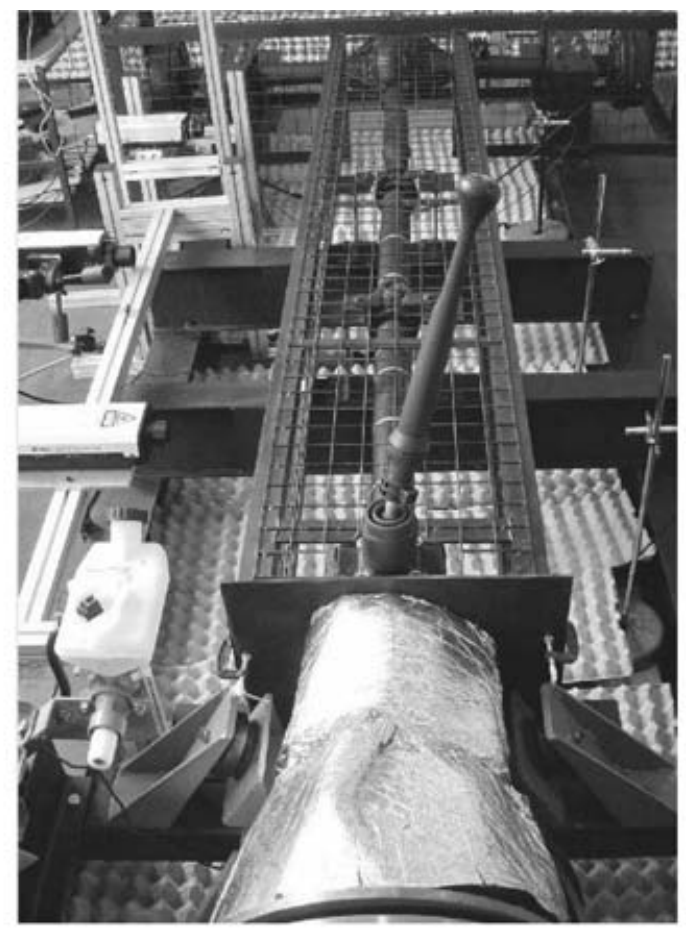

(b)

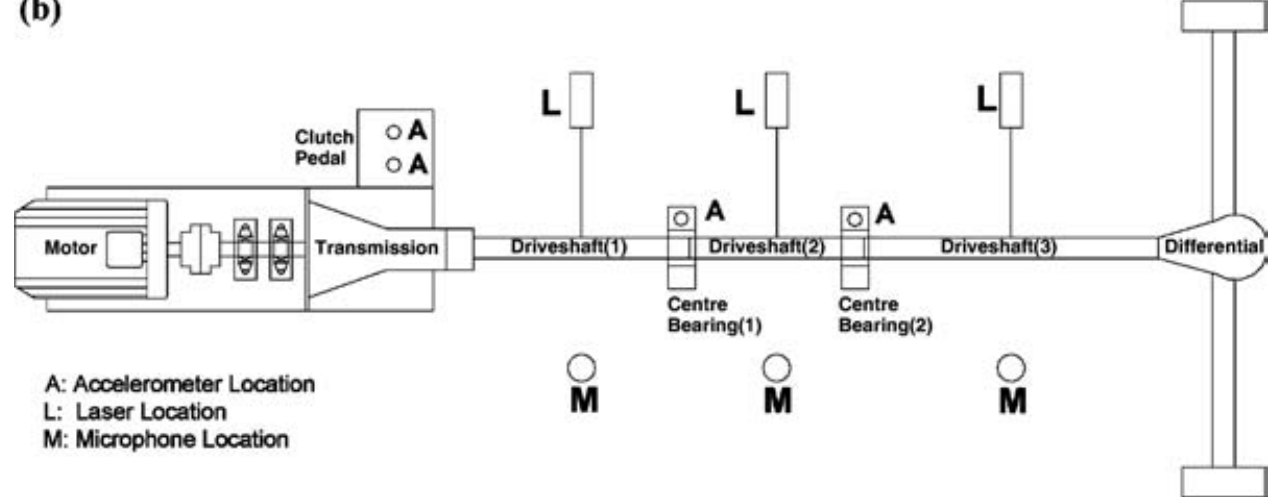

Fig. 2 (a) Three-piece driveline experimental rig and (b) schematic layout of the rig, showing the positions of various pick-ups

clonk as an elastoacoustic coupling in hollow thinwalled driveshaft tubes. Therefore, other vibrating structures contributing to the same mechanism of acoustic coincidence with the structure-borne wave, particularly the transmission bell housing, were effectively shielded. The characteristic response of such structures under clonk conditions was studied in reference $[\mathbf{1 3}]$.

The following monitoring equipment was used, enabling measurements of the transient response across the system. A schematic layout of the rig, showing the various pick-up points, is presented in Fig. 2(b).
1. Accelerometers are attached to the clutch pedal to monitor the clutch engagement/disengagement time intervals. The acceleration and velocity rates of the clutch pedal motion are captured in order to classify the applied excitation according to the driver's behaviour (see Fig. 3).

2. Accelerometers are located at the mount of the driveline centre support needle bearings to measure the transmitted vibration to the chassis.

3. Non-contact laser doppler vibrometers (LDVs) are aligned orthogonal to the rotation axis of the hollow driveshaft tubes to measure their vibration response. 


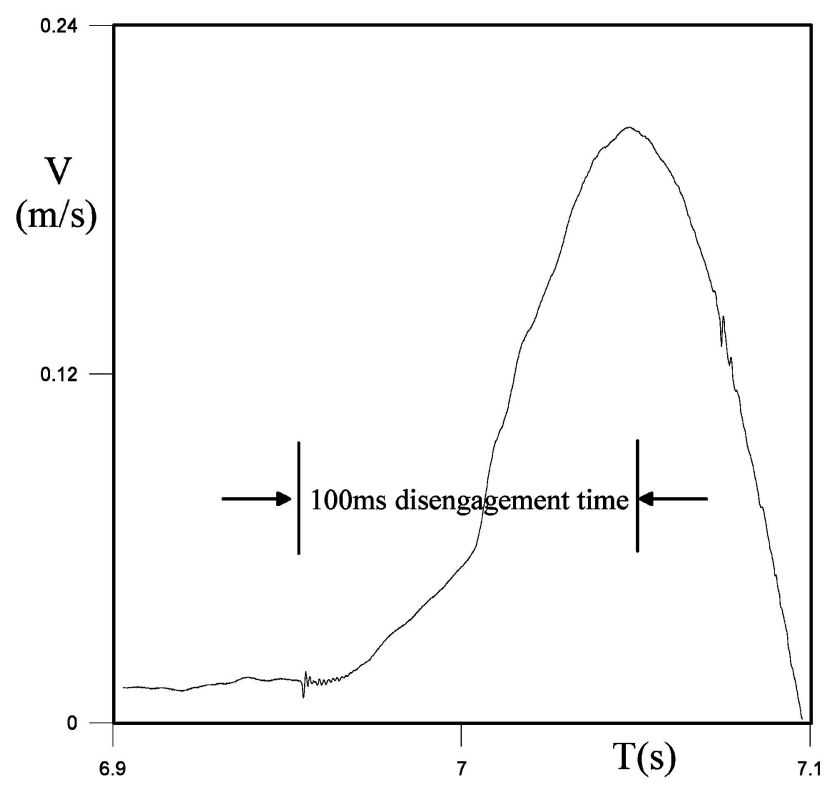

Fig. 3 Clutch disengagement corresponding to the behaviour of an aggressive driver

4. Freefield microphones are used to measure the radiated noise from the driveshaft tubes, transmission bell housing, and rear axle.

The background noise was recorded and its spectral content identified in order to avoid uncertainties in the test results. As can be seen in Fig. 4, the frequencies of background noise are substantially below the clonk range frequencies and mainly include harmonics from the electric motor, the gear meshing frequencies, and those radiated from the centre support bearings. The sampling rate of the recorded signal was carefully selected to be at least twice that of the highest frequency of interest $(5000 \mathrm{~Hz})$, and to be in accord with the requirements of the Nyquist criterion. Therefore, a sampling rate of 16384 samples/s was used to provide sufficient resolution in the area of the actual accelerative response (i.e. the impact duration). This is merely a fraction of the acquired measurement. Fourier spectra with a data capture window (constituting short-duration FFT spectra) are used to minimize the spectral leakage. Moreover, wavelet decompositions are employed to highlight the difference in time duration between the clonk peak and the accompanying ringing noise, so that the main spectral contributions in each event are easily discernible.

\section{EXPERIMENTAL RESULTS AND DISCUSSION}

Figures 5(a) and (b) show typical clonk velocity signals for the rear driveshaft (closest to the differential lash zone), corresponding to the configuration with a single solid-mass flywheel and the DMF respectively. The signals were measured using laser vibrometers, targeting the mid-span section of the shaft. The intensity of the captured phenomenon is lower in the case of the DMF in both magnitude and duration. The clonk signal traverses the tube, past the point of the laser. In most measurements, the clonk wave persists at least 3 times longer in the case of the solid flywheel configuration than with the DMF-based alternative. Similar observations can be made from Figs 5(c) and (d) for the corresponding

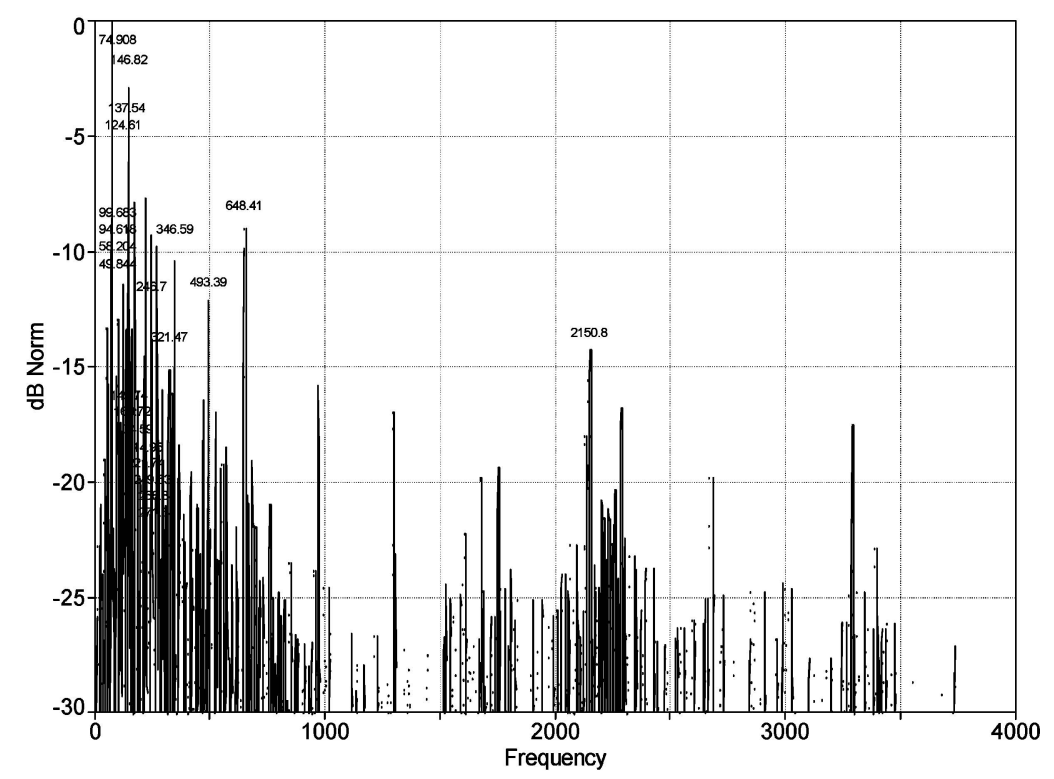

Fig. 4 FFT spectra of the background noise in the vicinity of the rear driveshaft 

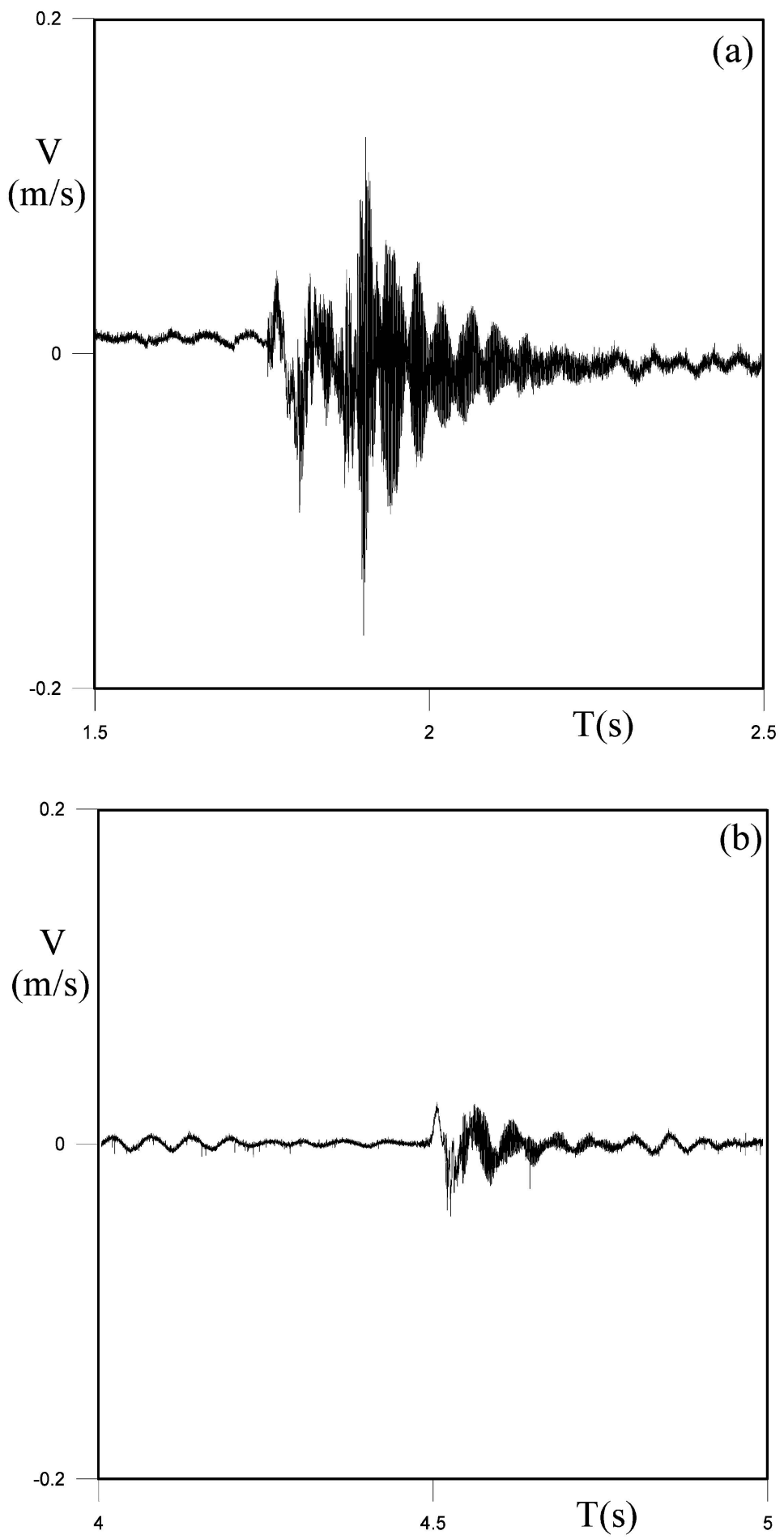

Fig. 5 Typical clonk vibration signals measured at the mid-span of the third shaft for (a) a solid flywheel and (b) a DMF; (c), (d) corresponding noise clonk signals

clonk noise signals that were captured by microphones in the vicinity of the third tube. Typically, there is attenuation of the radiated sound when a DMF is employed - of the order of $4 \mathrm{~dB}$ maximum for the frequency range of interest, where clonk manifests itself (i.e. $1500-4000 \mathrm{~Hz}$ ). In the experiments conducted, the radiated noise amplitude approached $106 \mathrm{~dB}$ (3.99 Pa) with the solid-mass flywheel, while in the case of the DMF the maximum noise output reached amplitudes of $102 \mathrm{~dB}(2.51 \mathrm{~Pa})$ for the most severe clutch actuations. This can be interpreted as a not very impressive performance of DMF, given the 

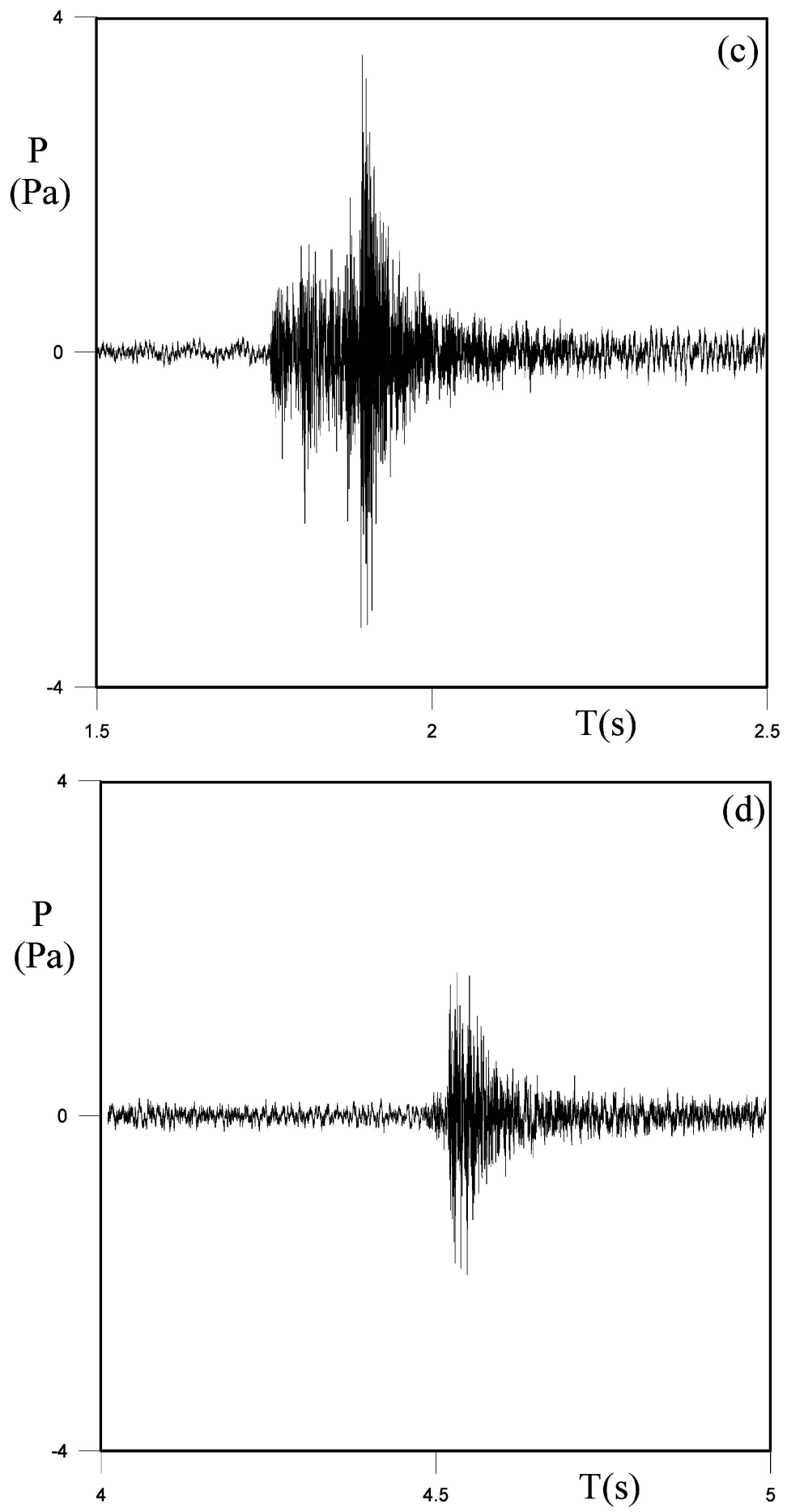

Fig. 5 (Continued)

significant additional cost of its installation, particularly in that it considerably reduces and smoothens the torque fluctuations transmitted through to the driveline. Further analysis of the frequency content of the signals is required in order to identify any beneficial qualitative characteristics, such as the sharpness of the metallic spectral content as a particular annoying NVH concern.
The main observation during the conducted experiments was a significant change in the quality of the recorded radiated noise when using the DMF. The acute metallic nature of high-frequency clonk noise observed in the case of a solid flywheel appeared to have been muted to a milder thump noise when DMF was used. This change is confirmed by the normalized FFT windowed spectra of Figs 6 
(a)

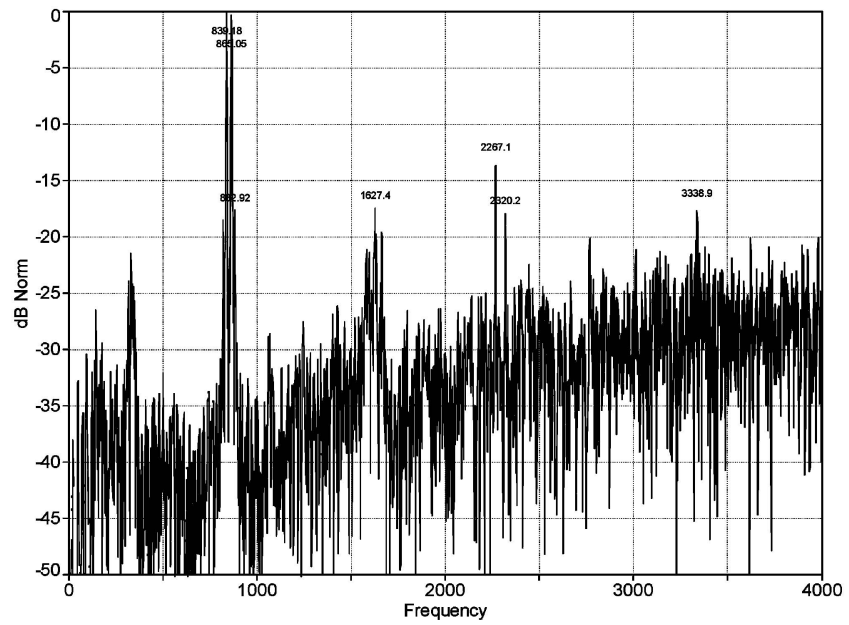

(b)

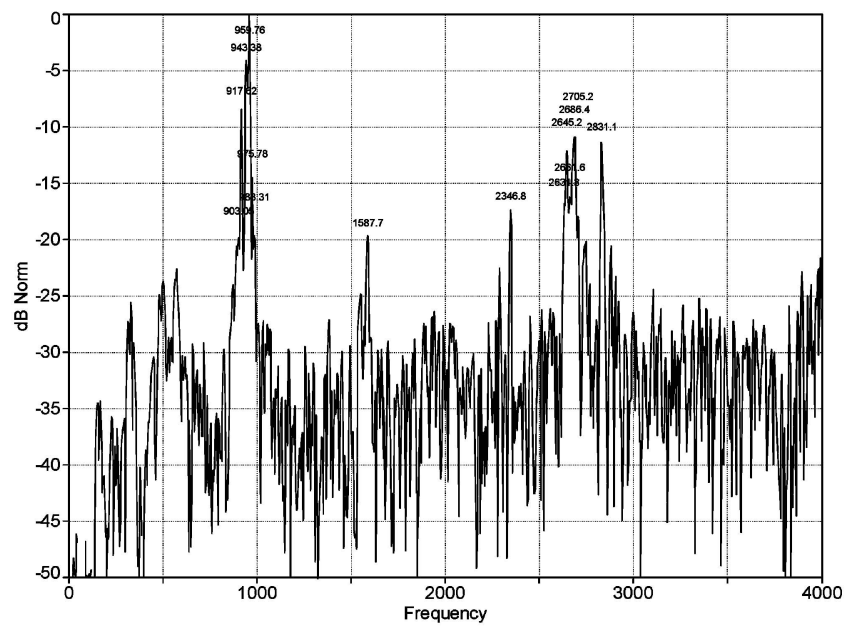

(c)

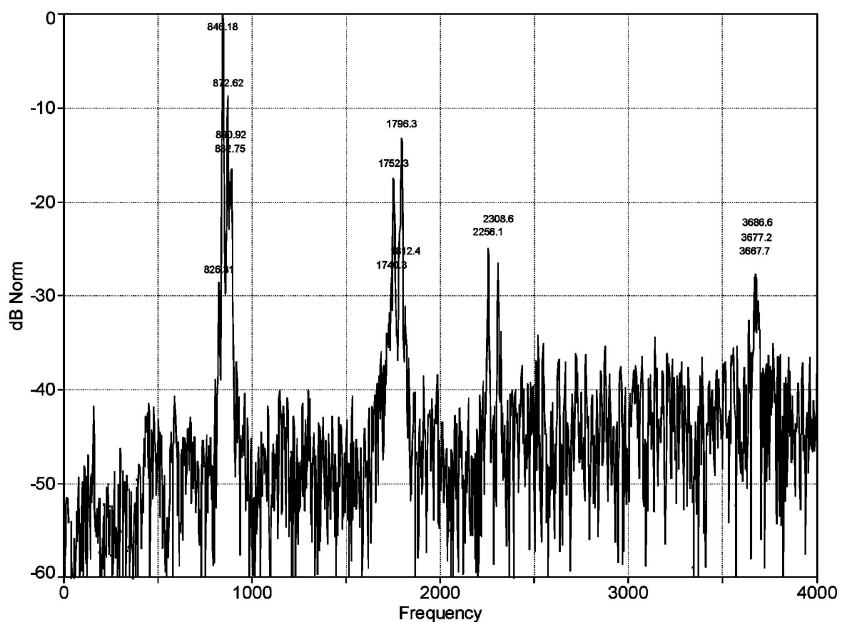

Fig. 6 Solid- and dual-mass flywheel configuration - FFT spectra of the vibration clonk signal for (a), (d) front,(b), (e) middle, and (c), (f) rear shafts

and 7. In Figs 6(a) to (c) the FFT spectra of the clonk signal at the mid-span of the three driveshaft pieces are shown for the case of the solid flywheel based drivetrain. The major highlighted frequencies cover approximately the range $800-3700 \mathrm{~Hz}$ corresponding to a variety of mode shapes from bending to breathing modes [12]. However, not every one of these modes is responsible for the clonk noise, since conditions leading to elastoacoustic coupling (coincidence of structural and acoustic modes) are required, as described in detail in reference [11]. In particular, the breathing modes are efficient noise 
(d)

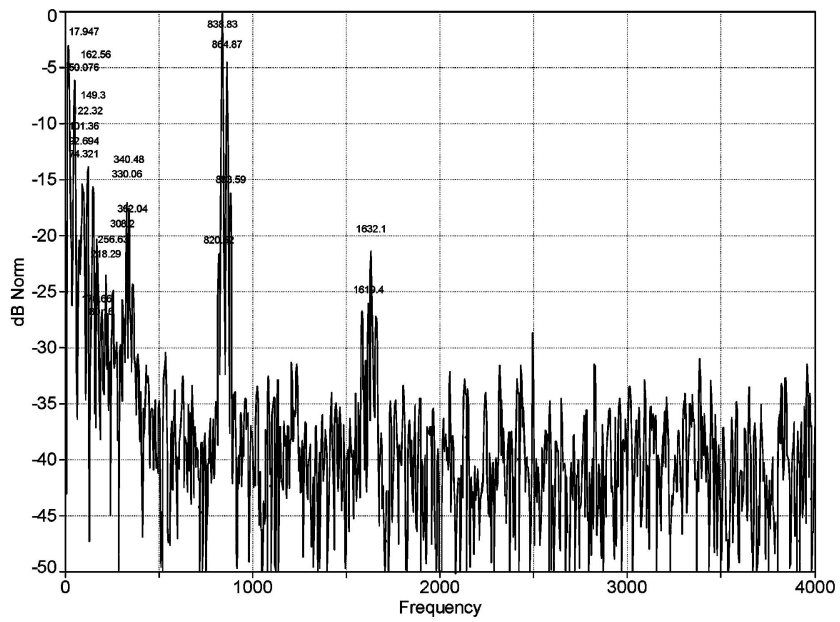

(e)

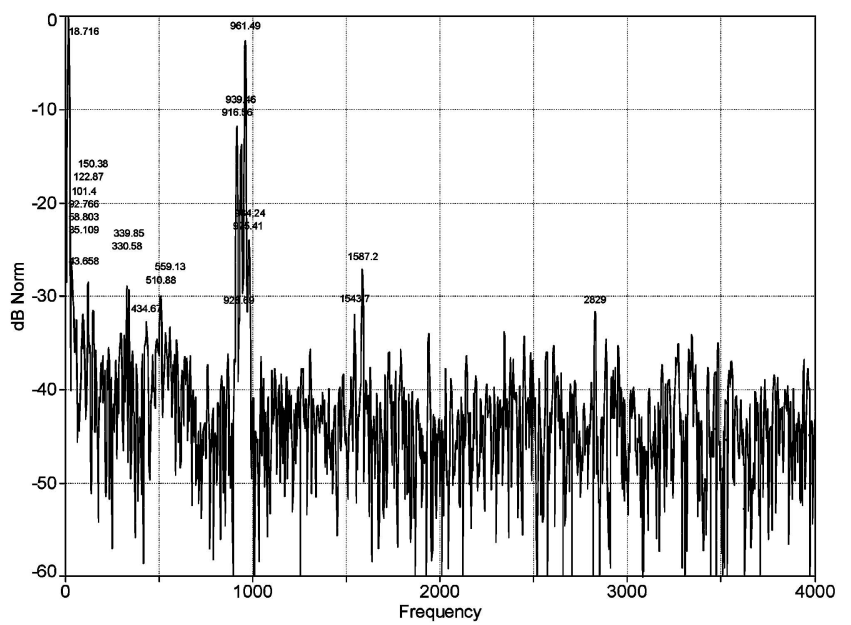

(f)

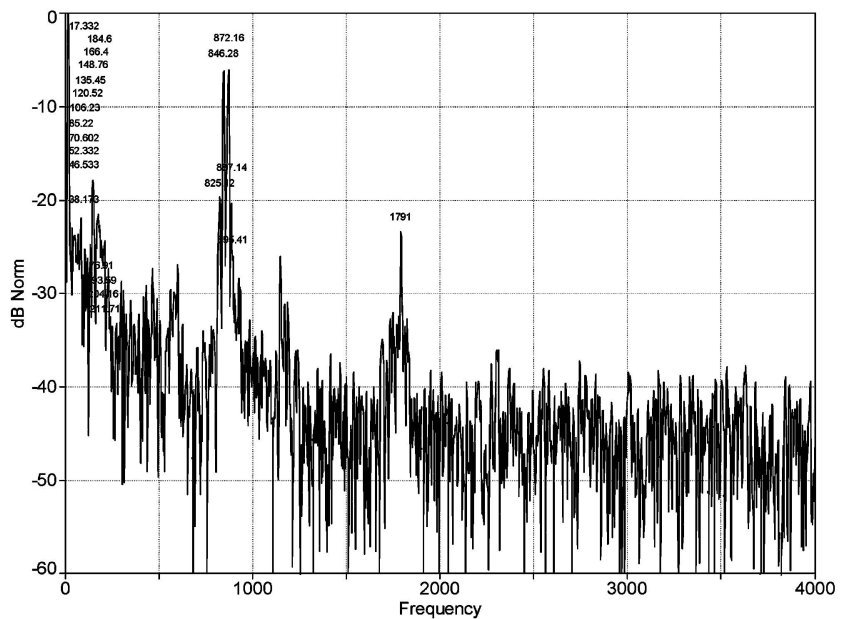

Fig. 6 (Continued)

radiators. These are the modes concentrated in the following two frequency bands: $2200-2700 \mathrm{~Hz}$ and $3300-3700 \mathrm{~Hz}$, as shown in the airborne noise spectral windows in Figs 7(a) to (c) for the three driveshaft tubes. These correspond to the cases of Figs 6(a) to (c). The structural waves travelling along the driveline after the sudden clutch actuation excite the aforementioned modes, leading to an acute metallic noise. The other frequencies present in the spectra represent the contributions from the electric motor, gear meshing frequencies, centre bearing speed-dependent primary vibrations, and bending 
(a)

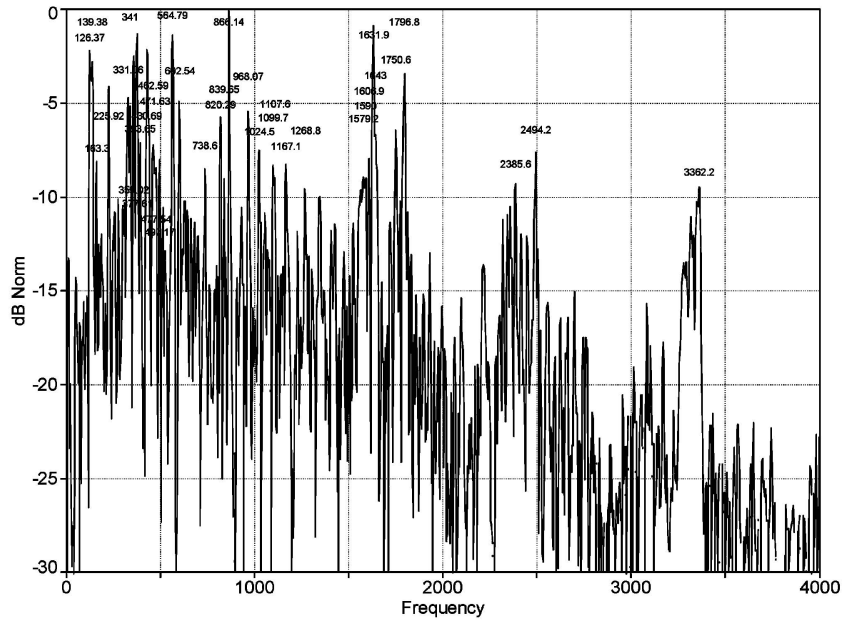

(b)

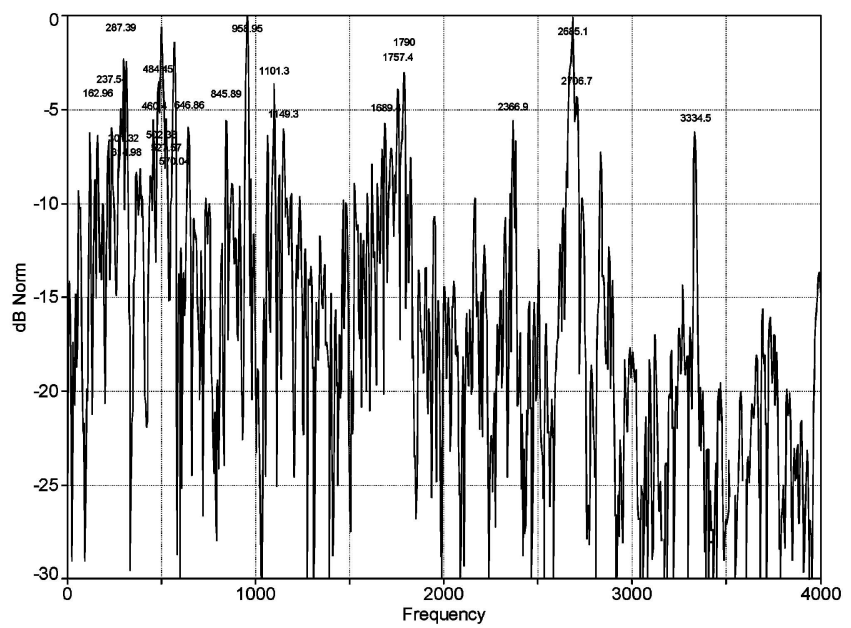

(c)

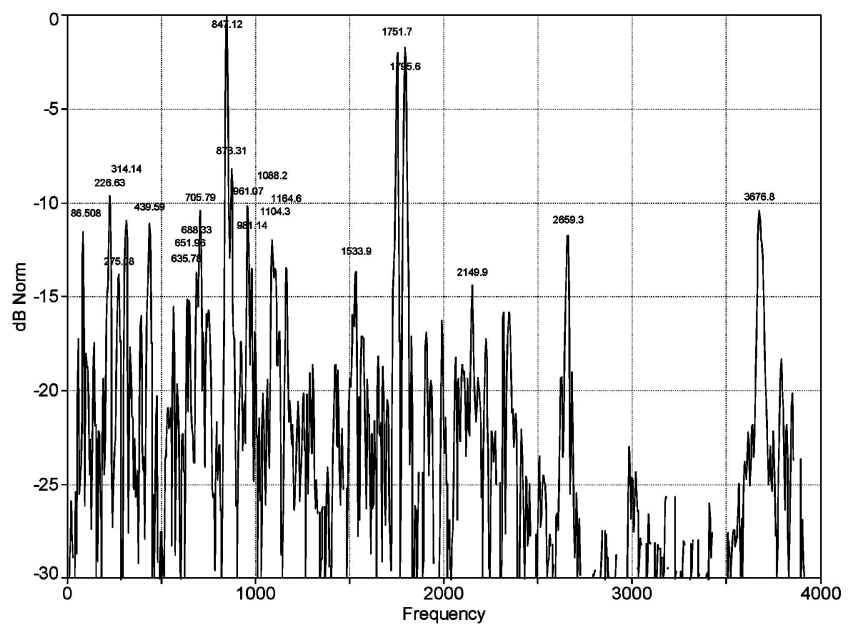

Fig. 7 Solid-and dual-mass flywheel configuration - FFT spectra of the noise clonk signal for (a), (d) front, (b), (e) middle, and (c), (f) rear shafts

and torsional modes of the driveshaft pieces. A full description of these is provided in reference [11].

In Figs 6(d) to (f) the normalized spectral windows at the mid-spans of the three tubes are shown for the DMF configuration. By comparing these with those in Figs 6(a) to (c) (for the case of the solid flywheel) it is possible to observe the persistence of the lower-frequency contributions (i.e. below $500 \mathrm{~Hz}$ ) and the attenuation of the higher frequencies (above $1500 \mathrm{~Hz}$ ). Similar phenomena have been observed in reference [9], where the effect of DMF was examined in terms of the rear axle differential vibration. The 
(d)

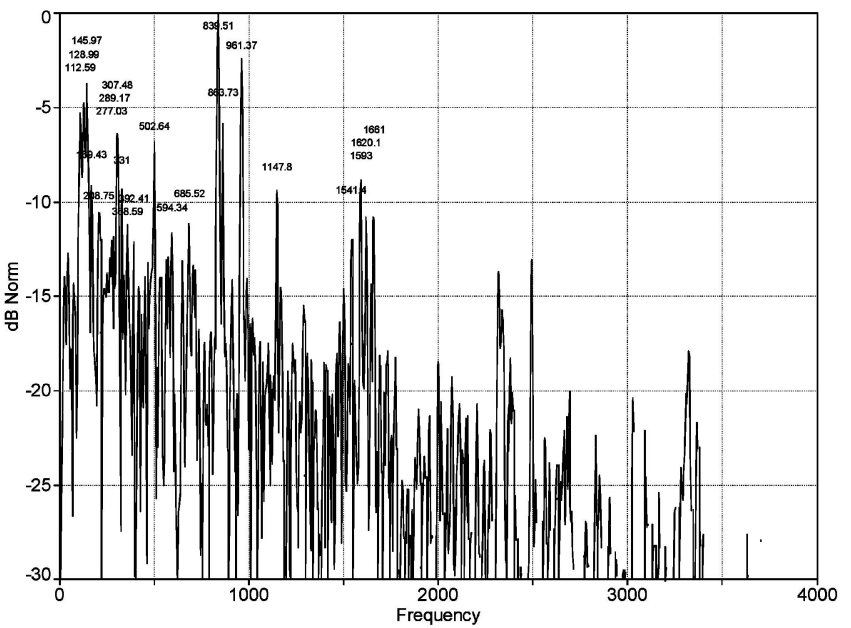

(e)

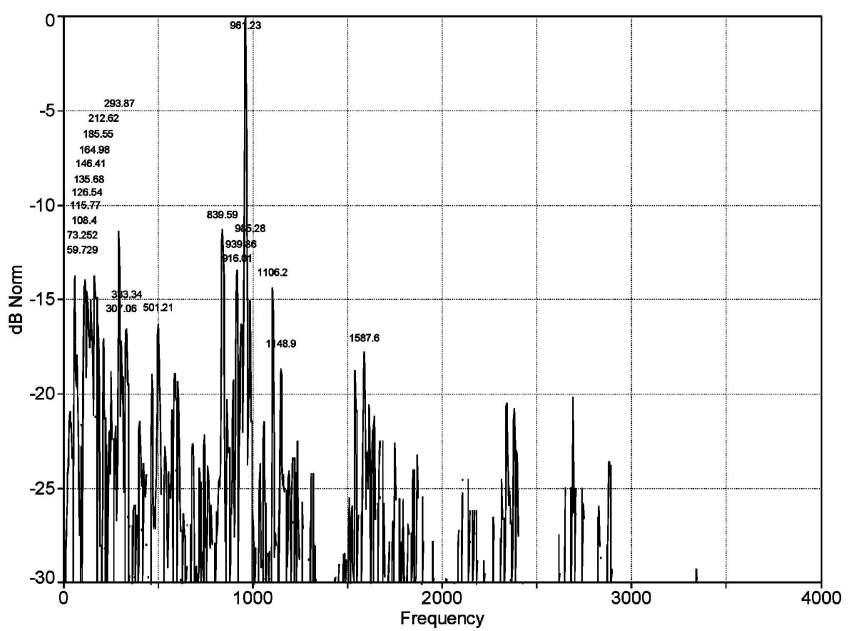

(f)

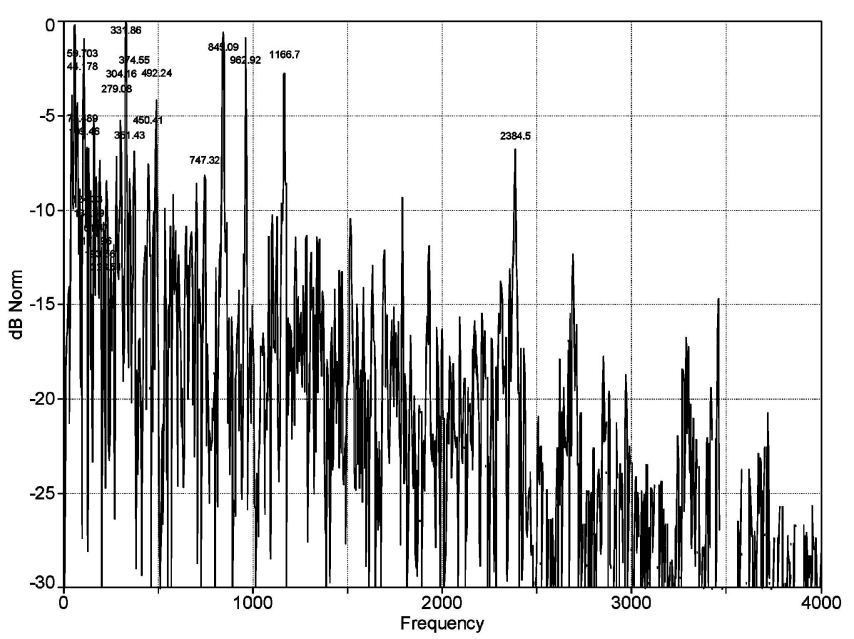

Fig. 7 (Continued)

main contributing frequencies were shifted towards the lower spectral content. This effect in clonk conditions eventually leads to alteration of the radiated noise quality, as the edge is taken off the sharpness of the breathing modes. The increased inertia of the DMF system not only has a significant impact on the transmission of engine vibration to the drivetrain system under steady state conditions but also notably affects the drivetrain behaviour under transient impacts during aggressive clutch actuation. The above observations are markedly visible in the windowed airborne noise spectra in Figs 7 (d) to (f). Only in a few extreme cases of fast clutch actuation has sufficient excitation of some of the high-frequency 
breathing modes in order for them to appear in the spectra been observed. However, these cases were just exceptional compared with the majority of the conducted experiments. In Fig. 8 the magnified mode shapes corresponding to breathing modes of the driveline, which are not excited because of the presence of DMF, are shown. These are the most effective clonk noise radiators, responsible for the metallic character of the signal. The DMF installation has an insignificant effect on the lower-frequency contributions contained in the clonk signal, as observed by comparison of Figs 6 and 7 .

The above observations are also supported by the results in Figs 9 and 10, where wavelet decompositions of the clonk noise signal for the three driveshaft tubes are presented for the two examined configurations. In Fig. 9, the wavelet decomposition is shown for the case of a solid-mass flywheel, where the contribution of high frequencies (above $2000 \mathrm{~Hz}$ ) can clearly be observed (in the lighter shade). The main clonk event(s) is accompanied with a ringing noise with a frequency signature comprising two contributions: the first occurs just below $1000 \mathrm{~Hz}$ and the second slightly above $1500 \mathrm{~Hz}$. The duration of this secondary event, which is of no less importance for the drivetrain vibration, is higher than $300 \mathrm{~ms}$. On the other hand, in the wavelets of Fig. 10 there is a considerably reduced effect from the frequencies above $2000 \mathrm{~Hz}$ for all the shafts. The ringing noise content is also attenuated in terms of both amplitude and duration, lasting less than $300 \mathrm{~ms}$ even in the most extreme cases. It is noteworthy that

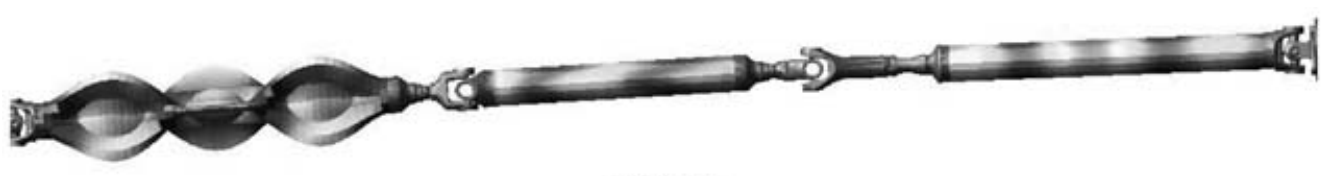

$2454 \mathrm{~Hz}$

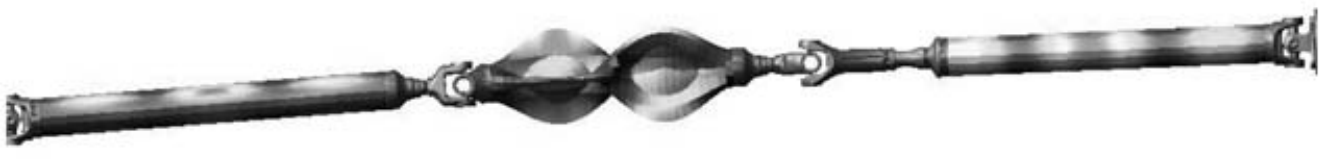

$2457 \mathrm{~Hz}$

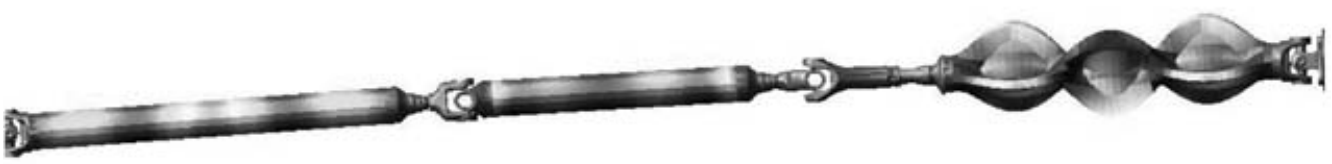

$2502 \mathrm{~Hz}$

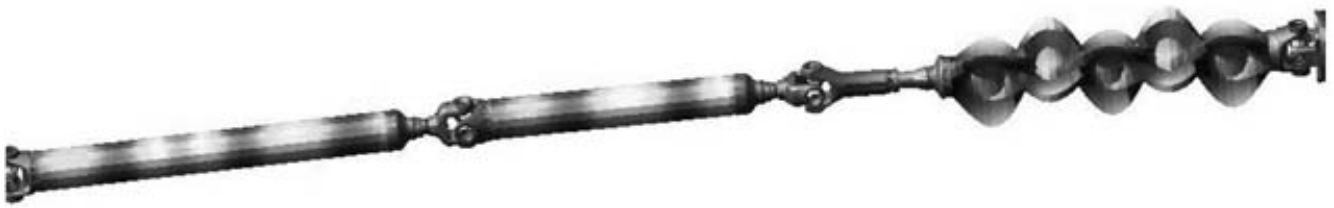

$3348 \mathrm{~Hz}$

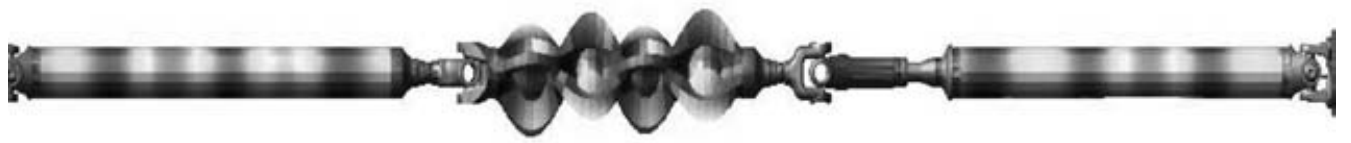

$3540 \mathrm{~Hz}$

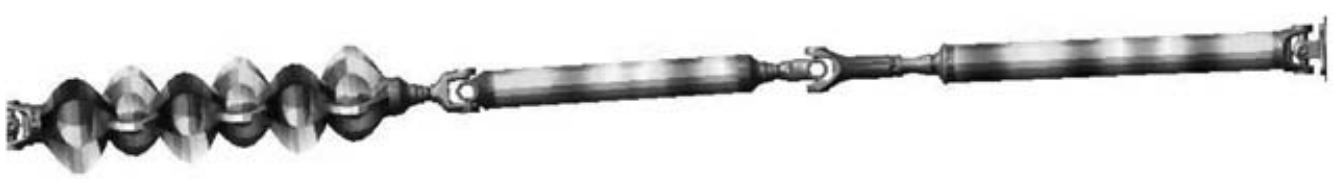

$3634 \mathrm{~Hz}$

Fig. 8 Magnified mode shapes of the main attenuated breathing modes under a DMF configuration 
(a)
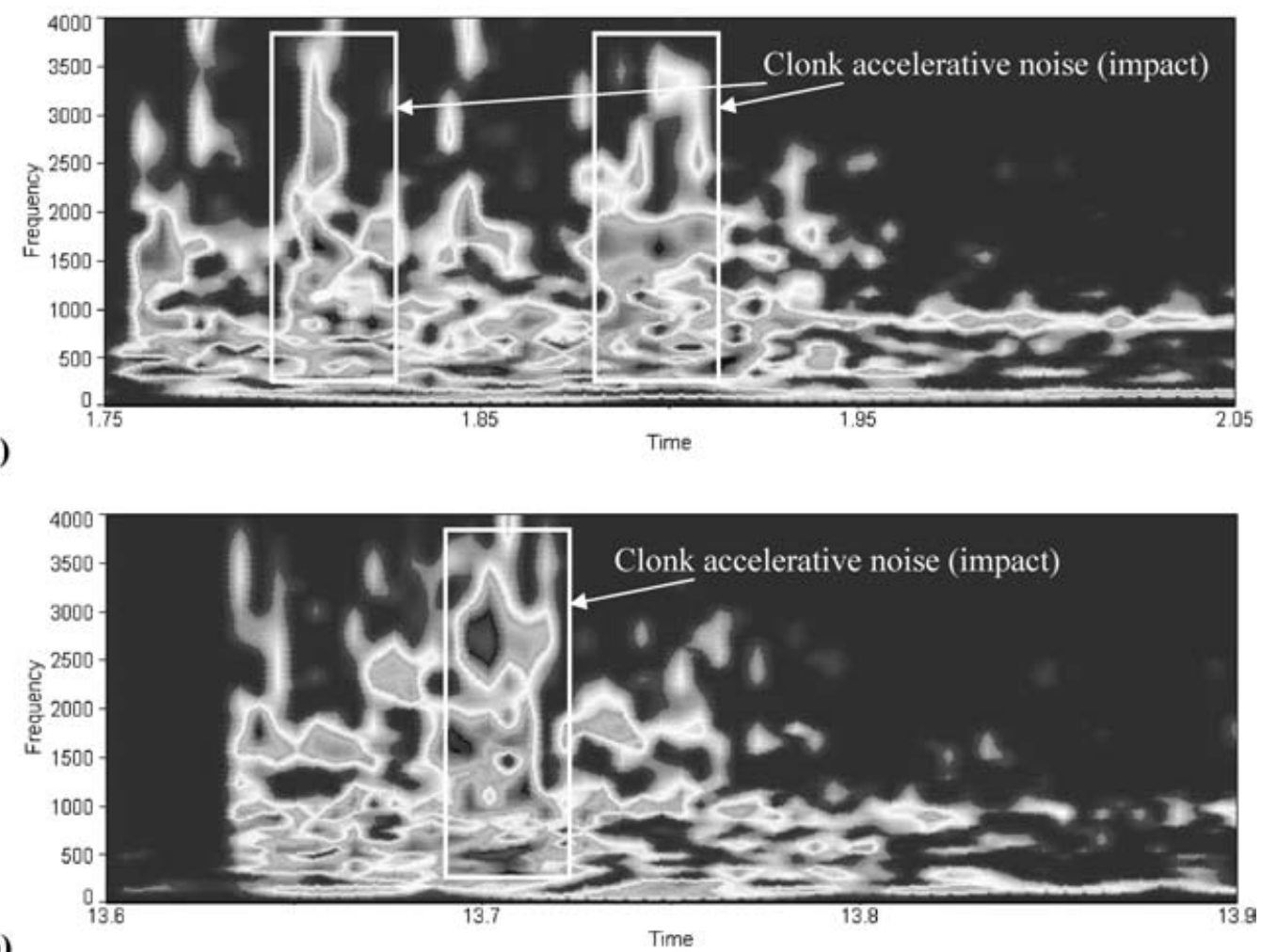

(b)

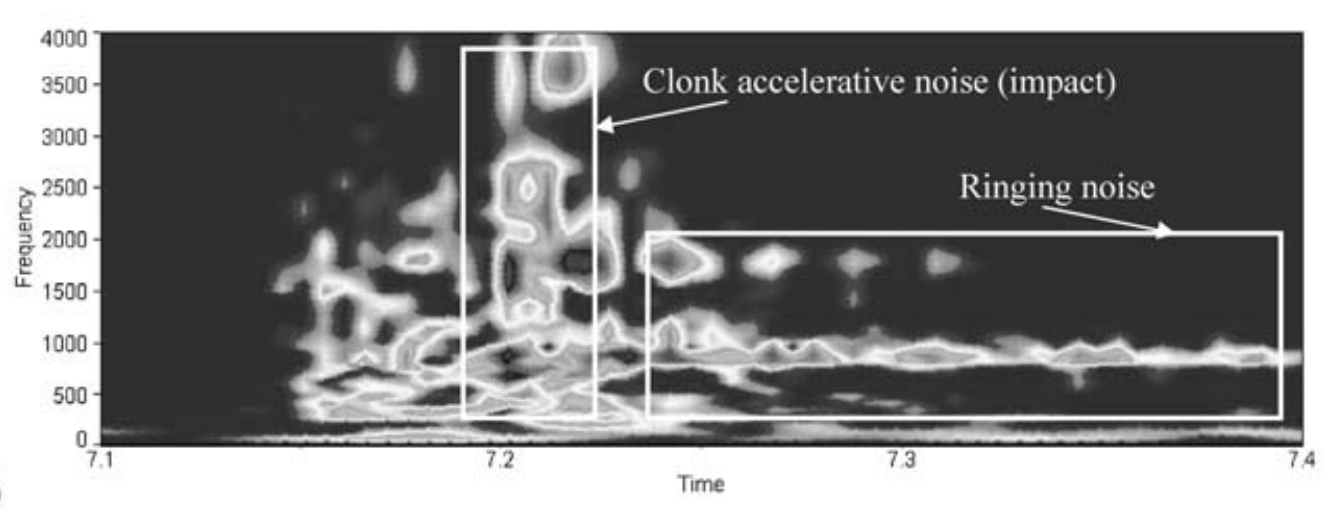

(c)

Fig. 9 Solid flywheel configuration - wavelets of the clonk noise signal for (a) front, (b) middle, and (c) rear shafts

the effect of DMF on ringing noise has already been revealed in investigations concerning gear rattle under steady state conditions $[\mathbf{7}, \mathbf{9}]$.

\section{CONCLUSIONS}

The effect of DMF on the transient vibro-impact clonk phenomenon has been examined. The conducted experiments have revealed a significant alteration in the vibration and noise signatures in comparison with drivetrain systems that make use of solid-mass flywheels. Although the change is not dramatic in terms of the overall amplitude levels for radiated noise, the main breathing modes responsible for the acute metallic nature of clonk are no longer excited significantly by the transmitted torque wave with a reduced energy content. Therefore, the effect of DMF on the quality of the transmitted power across the driveline is evident.

Moreover, the total duration of the main clonk peak wave is reduced. A similar effect is also observed in the duration of the accompanying ringing noise. It appears that the use of the DMF as a palliative measure can have a beneficial effect on the transient clonk response by transforming it to a milder form of radiated noise. The excitation on the main breathing structural modes of the hollow driveshaft tubes 
(a)
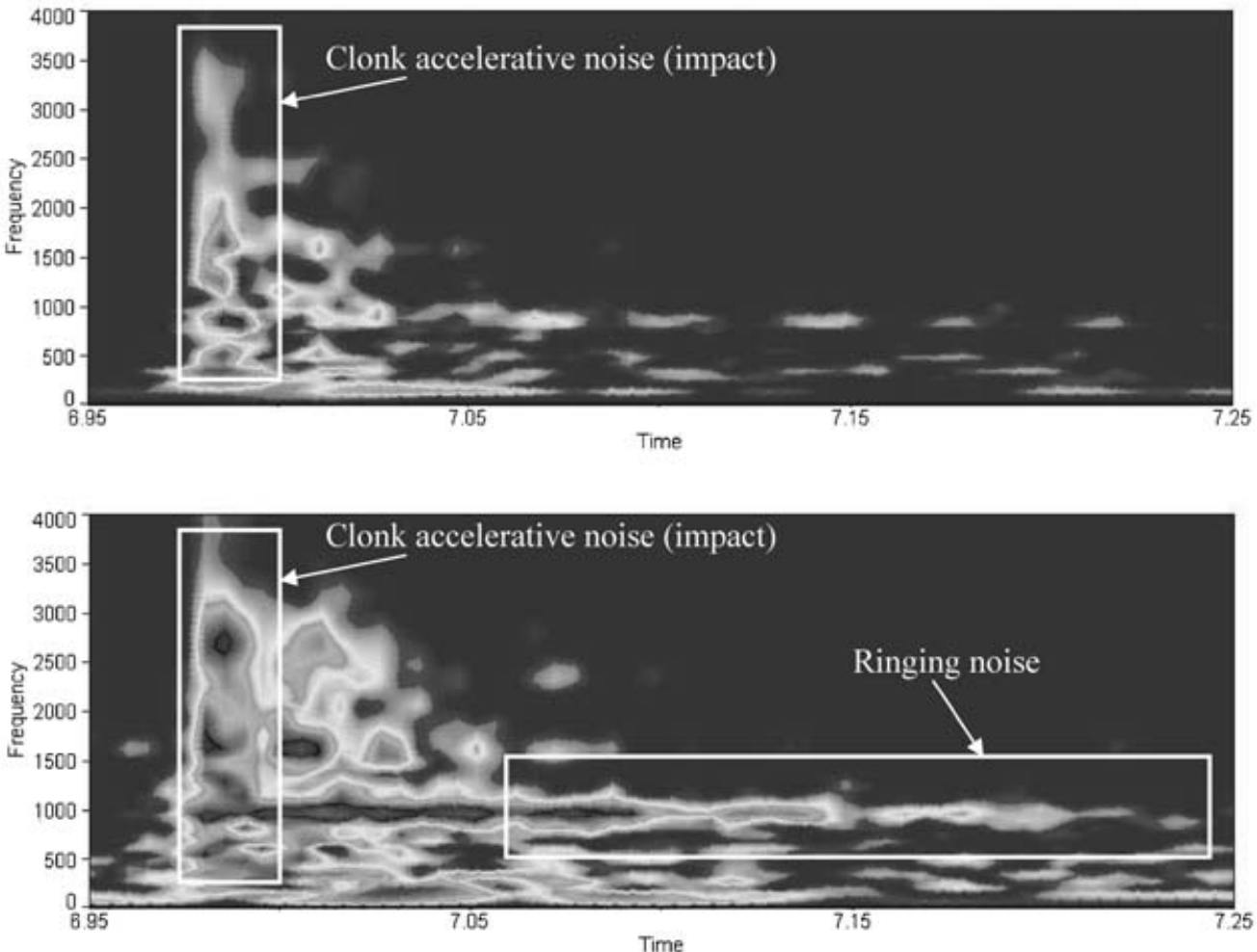

(b)

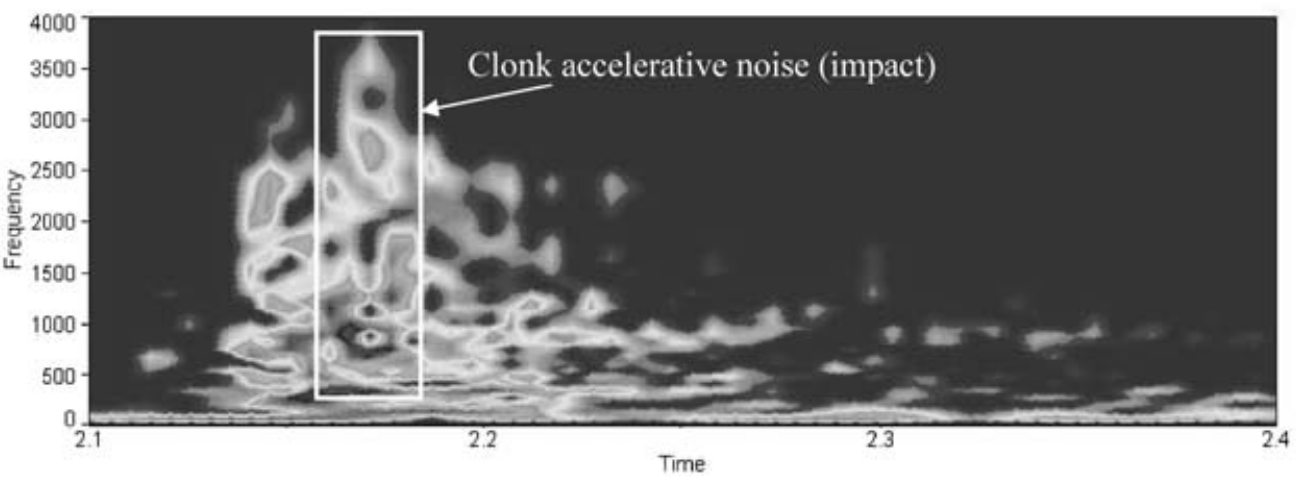

(c)

Fig. 10 DMF configuration - wavelets of the clonk noise signal for (a) front, (b) middle, and (c) rear shafts

is attenuated. This improves the occupants' perception of the transient vibro-impact phenomena in the drivetrain that are caused by abrupt clutch actuation.

\section{ACKNOWLEDGEMENTS}

The authors wish to express their gratitude to Ford Motor Company, MSC Software, and the Vehicle Foresight Directorate (EPSRC and DTI) for sponsorship and financial support extended to this research project. The authors also wish to acknowledge the contribution of Bruel and Kjaer UK in supporting the experimental effort.

\section{REFERENCES}

1 Rahnejat, H. Multi-body Dynamics: Vehicles, Machines and Mechanisms, 1998 (PEP (IMechE), Bury St Edmonds and SAE, Warrendale, Pennsylvania).

2 Littlefair, G. P. Arc spring sliding friction within the dual mass flywheel, MSc Thesis, Loughborough University, Loughborough, UK, 2004.

3 Drexl, H. J. Torsional dampers and alternative systems to reduce driveline vibrations. SAE paper, 870393, 1987.

4 Drexl, H. J. Truck clutches for the 90s - higher torques, efficient torsional dampening and electronic control. SAE paper 892475, 1989.

5 Petri, H. and Heldingfeld, D. The hydraulic torsion damper - a new concept for vibration damping in powertrains. SAE paper 892447, 1989. 
6 Schnurr, M. Development of the super-long-travel dual mass flywheel. In Proceedings of 4th LUK International Symposium, Baden-Baden, Germany, 1990, pp. 55-80.

7 Reik, W. Torsional vibration isolation in the drivetrain. An evaluative study. In Proceedings of 4th LUK International Symposium, Baden-Baden, Germany, 1990, pp. 125-146.

8 Laschet, A. Computer simulation of vibrations in vehicle powertrains considering nonlinear effects in clutches and manual transmissions. SAE paper 941011, 1994.

9 Steinel, K. Clutch tuning to optimize noise and vibration behaviour in trucks and buses. SAE paper 2000-01-3292, 2000.

10 Gnanakumarr, M., Theodossiades, S., Rahnejat, H., and Menday, M. Impact induced vibration in vehicular driveline systems: theoretical and experi- mental investigations. Proc. IMechE, Part K: J. Multibody Dynamics, 2005, 219, 1-12.

11 Theodossiades, S., Gnanakumarr, M., and Rahnejat, H. Root cause identification and physics of impact induced driveline noise in vehicular powertrain systems. Proc. IMechE, Part D: J. Automobile Engineering, 2005, 219, 1303-1319.

12 Theodossiades, S., Gnanakumarr, M., Rahnejat, H., and Menday, M. Mode identification in impactinduced high-frequency vehicular driveline vibrations using an elasto-multibody dynamics approach. Proc. IMechE, Part K: J. Multi-body Dynamics, 2004, 218, 81-94.

13 Menday, M., Rahnejat, H., and Ebrahimi, M. Clonk: an onomatopoeic response in torsional impact of automotive drivelines. Proc. IMechE, Part D: J. Automobile Engineering, 1999, 213, 349-357. 